\title{
Comunicación, ética y feminicidio: Contextos de una crisis de representación en la prensa de México
}

\author{
Javier Juárez Rodríguez ${ }^{1}$
}

\section{Resumen}

Recepción: 25 de julio de 2017 / Aprobación: 28 de setiembre de 2017

Ciudad Juárez se ha convertido en paradigma de la consolidación de un sistema patriarcal extremo que protege y potencia la impunidad sobre los feminicidios y desapariciones forzosas de niñas y mujeres. Entre 1993 y 2017 casi 2.000 mujeres han sido asesinadas en la ciudad y decenas siguen desaparecidas. El presente artículo explica los factores que alimentan la perpetuación de este sistema perverso capaz de ejecutar campañas de manipulación y desinformación, profundizando en el papel y la responsabilidad ética de los y las periodistas a la hora de informar. Para el desarrollo de nuestra investigación hemos aplicado de forma transversal la perspectiva de género, recurriendo a metodologías cuanti-cualitativas, entre ellas entrevistas inéditas en profundidad a periodistas, autoridades y activistas quienes han investigado estos sucesos en detrimento de las mujeres y la sociedad mexicana. El trabajo es resultado de un análisis plural y metodológico tras ocho años de seguimiento, recopilando reflexiones sobre el papel y la responsabilidad social y ética de medios y periodistas.

\section{Palabras clave}

Periodismo; violencia de género; desaparición forzosa; patriarcado; Ciudad Juárez

\section{Abstract}

Ciudad Juarez has become a paradigm of the consolidation of a patriarchal system that protects and enhances impunity for feminicide and forced disappearances of girls and women. Between 1993 and 2017 nearly 2.000 women have been killed in the city and dozens are still missing. This article explains the factors fueling and perpetuating this evil system capable of running manipulation and disinformation campaigns, delving into the role and ethical responsibility of journalists. For the development of this research project, we have transversally applied a gender perspective, using quantitative and qualitative methodologies, interviewing journalists, authorities and activists who have investigated these events to the detriment of women and Mexican society. This work is the result of a plural and systematic analysis after eight

1 Español. Doctor en Periodismo por la Universidad Complutense de Madrid, España. ProfesorInvestigador a Tiempo Completo en la Facultad de Comunicación de la Universidad de Medellín, Colombia. Correo electrónico: jjuarez@udem.edu.co 
years of monitoring, collecting reflections on the role of journalists and their social and ethical responsibility of media workers and management.

\section{Keywords}

Journalism; gender violence; forced disappearance; patriarchy; Ciudad Juarez

\section{Resumo}

Cidade Juárez tem-se convertido em um paradigma da consolidação de um sistema patriarcal que protege e reforça à impunidade dos femninicídios e desaparecimentos forçados de meninas e mulheres. Entre 1993 e 2017, cerca de 2.000 mulheres foram mortas na cidade e dezenas ainda estão desaparecidas. Este artigo explica os fatores que perpetuam este sistema perverso, capaz de fazer campanhas de de manipulação e desinformação. Também se analiza o papel ético e responsabilidade dos jornalistas quando informam. Para o desenvolvimento da nossa pesquisa aplicamos a perspectiva de gênero, utilizando metodologias quantitativas e qualitativas, fazendo entrevistas a profundidade a jornalistas, funciónários e ativistas que investigam o tema tem pesquizado estos asuntos tam detrimentes para as mulheres e sociedade mexicana. O trabalho é o resultado de uma análise plural e metodológico após de oito anos de acompanhamento, coletando reflexões sobre o papel ea responsabilidade social e ética dos meios de comunicação e jornalistas.

\section{Palavras chave}

Jornalismo; violência de gênero; desaparecimento forçado; patriarcado; Cidade Juarez

\section{Introducción}

Debemos comenzar señalando que, pese a que Ciudad Juárez se ha convertido, lamentablemente, en un ejemplo de consolidación de un sistema patriarcal férreo, toda la República mexicana es víctima, en la actualidad, del fortalecimiento de actores misóginos y hegemónicos que controlan y ostentan el poder (Castells, 2009). Lo anterior potencia el fortalecimiento de un sistema de violencia estructural contra las mujeres amparado en una total impunidad. Solo entre 1985 y 2010 más de 36.600 mujeres fueron asesinadas en México y más de 4.000 permanecen en calidad de desaparecidas ${ }^{2}$ (Incháustegui, 2012, p. 23), cifras que develan una violencia específica contra las mujeres que sigue en aumento, como lo demuestra el hecho de que entre 2007 y 2016 más de 11.000 mujeres hayan sido asesinadas en toda la república, crímenes que, en su mayoría, vienen ligados a una total impunidad ${ }^{3}$.

Debemos englobar y analizar los feminicidios y desapariciones forzosas de niñas y mujeres de Ciudad Juárez no como un fenómeno causal o coyuntural,

$2 \quad$ Datos obtenidos del Informe Violencia feminicida en México 1985-2010: Características, tendencias y nuevas expresiones en las entidades federativas (Comisión Especial para el Seguimiento de los Feminicidios, ONU Mujeres, Instituto Nacional de las Mujeres, 2012). feminicidios cometidos en México quedan impunes. 
sino como producto de "pactos entre hombres" (Amorós, 1994) dentro de un sistema controlado y diseñado por varones. Solo dentro de un patriarcado extremo podemos entender la construcción y consolidación de un sistema que todo lo abarca, que todo lo controla, y que sustenta en la violencia estructural contra niñas y mujeres uno de sus bastiones de máxima expresión como "una manifestación extrema de la violencia patriarcal" (Varela, 2005, p. 248).

Ante esta realidad, solo el trabajo y la lucha feminista intensificada en las últimas décadas han conseguido visibilizar y denunciar la cadena de complicidades que subyace tras todo un sistema que engloba el poder político, el judicial y los medios de comunicación. Ante el poder casi inexpugnable de los actores machistas hegemónicos, solo el esfuerzo de mujeres, activistas y feministas, ha conseguido hacer frente a los abusos y visibilizar la red de complicidades existente entre los diferentes actores misóginos que ejercen el poder. Esta lucha, cimentada en movimientos de sororidad, entendida como una solidaridad específica entre mujeres que supera diferencias o discrepancias para unir y sumar esfuerzos, voluntades y capacidades contra el patriarcado (Lagarde, 2012, p. 34), ha puesto luz sobre uno de los ejemplos paradigmáticos de permisividad de las autoridades y su nulo interés en esclarecer y erradicar la violencia estructural que sufren niñas y mujeres como es el caso de Ciudad Juárez.

El Estado ha consolidado y fortalecido el dominio patriarcal, potenciando un sistema que ha permitido la normalización y la minimización de la violencia contra las mujeres. Durante los últimos 25 años (1993-2017), las autoridades han tratado de ocultar lo que algunas investigadoras, como Silvia Giletti, han definido como un femigenocidio (Giletti, 2014) de niñas y mujeres por una doble condición clase/género, esto es por ser mujeres pobres.

El término feminicidio tiene sus orígenes en la palabra feminicide, expresión que consiguieron con mucho esfuerzo acuñar las investigadoras Diana Rusell y Jane Caputi en la década de 1980, y que surge con una clara intención política: denunciar y visibilizar el componente misógino que subyace en estos crímenes, obviados a través del empleo de palabras neutras como homicidio o asesinato (Toledo, 2009). La aceptación y el uso del término feminicidio han provocado durante décadas una profunda controversia entre detractores de su empleo y defensores del mismo para visibilizar una realidad oculta y silenciada. Lo que no se nombra no existe (Kapuscinski, 2002), por lo que el empleo del término implica mucho más que un debate lingüístico menor y aboga por la visibilización de una realidad silenciada.

Los feminicidios son la expresión del desprecio y el odio del hombre hacia la mujer, fruto de un esquema socio-cultural dominado por el patriarcado. El lenguaje es pieza clave para el control, el dominio y la consolidación de mallas de poder (Foucault, 1999), para lograr el control de la sociedad. En 
este sentido, el papel de medios y periodistas es fundamental para visibilizar, o no, esta realidad; para dar voz a los silenciados y nombrar lo que trata de ocultarse por parte de los actores que ostentan el poder. Por todo ello, aún hoy existen posturas enfrentadas e irreconciliables a la hora de abordar hechos vinculados a la violencia misógina y, sobre todo, elementos dispares que distancian claramente los valores que priman en la "ética" periodística.

Por todo lo anteriormente expuesto, el objetivo principal planteado en nuestra labor investigativa se centra en analizar las respuestas gubernamentales aportadas ante los episodios de desapariciones forzosas y feminicidios en Ciudad Juárez entre 1993 y 2017. El trabajo es reforzado por objetivos específicos que han fortalecido nuestra labor investigativa y guiado el carácter científico de esta. En primer lugar, y desde una óptica crítica, se analizan trabajos realizados por periodistas e investigadores, así como su perspectiva de los hechos investigados, adentrándonos en el estudio del papel de la ética periodística para construir las narrativas mediáticas de los diversos tipos de violencia ejercida contra mujeres y niñas. En segundo lugar, se analiza el lenguaje, las estrategias y las campañas desarrolladas por autoridades y administraciones para la minimización de los casos mencionados. Por último, profundizamos en la importancia de la reproducción de estereotipos de género en los medios, algo que ha buscado y busca la culpabilización de la víctima y la justificación de estos crímenes.

\section{La importancia del lenguaje}

Ser mujer en Juárez es un factor de riesgo adicional en una ciudad (Juárez) y un país (México) históricamente violentos por numerosos factores endémicos. Este elemento de riesgo adicional que conlleva el hecho de ser mujer, se agudiza aún más si se es de clase humilde. La doble condición mujer pobre ha sido y es sinónimo de desprotección por parte de un Estado indolente (Robles, 2010). Las diferentes administraciones, de diferentes y cambiantes formaciones políticas, en todos sus ámbitos, municipal, estatal y federal, han ejercido una labor de permisividad y desprotección de las propias víctimas, que no puede ni debe ser entendida en ningún caso como consecuencia de una falta de medios o recursos, sino como parte de un sistema patriarcal que oculta sus omisiones y potencia una impunidad que se prolonga por 25 años. Han existido y existen estrategias y campañas impulsadas desde las autoridades mexicanas para propiciar la desinformación entre medios y ciudadanía en relación con los casos de secuestros y asesinatos sistemáticos de mujeres y niñas (feminicidios).

En Ciudad Juárez ha habido una campaña de silencio que se prolonga durante poco más de las últimas dos décadas, para ocultar un exterminio sistemático de niñas y mujeres que cuenta con el amparo de las propias autoridades, lo que agudiza la dificultad a la hora de desarrollar trabajos de investigación que traten de esclarecer estos hechos. Como señalábamos, el 
uso intencionado de los mensajes ha sido constante a lo largo de todos estos años; el lenguaje es la base sobre la que se inicia el proceso comunicativo y, al mismo tiempo, la cadena de información o desinformación. La prensa es reflejo de la calidad democrática de la sociedad y viceversa. En este sentido, el uso y control del léxico y de los mensajes que los diferentes medios lanzan a la sociedad es objeto codiciado por los actores que ostentan el poder. En este punto, el periodismo juega, o debería jugar, un papel primordial, no como altavoz de los mensajes oficiales de los actores patriarcales, sino como contrapoder (Castells, 2009). No podemos obviar, además, que los feminicidios sexuales sistemáticos de mujeres y niñas forman parte de un discurso particular entre hombres (Segato, 2013), sustentado en la violencia, escrito sobre el cuerpo de las mujeres y fruto de pactos patriarcales (Ravelo, 2011).

Desde el inicio de la documentación de los casos de feminicidios se generará una progresiva campaña desinformativa puesta en marcha desde las autoridades. Esta estrategia se basará, como explica el investigador Agustín García (2002), en la modificación, el encubrimiento y la alteración de aspectos sustanciales, necesarios y relevantes de la realidad, lo que imposibilita entender e interpretar los hechos, desvirtuando la realidad. También, los medios y las personas profesionales de la información desempeñarán un papel fundamental a la hora de analizar esta realidad ya que, como señala Xosé López (2010), el periodismo no actúa como un espejo, sino que construye una imagen del mundo y difunde una realidad; por ello, el papel del periodista se convierte en un permanente "filtro" que decide lo que el público debe conocer, garantizando que no manipula ni desinforma.

Es prioritario entender y analizar la importancia de la conceptualización del patriarcado, ya que, quienes tienen el poder de dar nombre a las cosas, las conceptualizan, hacen que "existan" (López, 2010). En este sentido, ha resultado fundamental la batalla por conceptualizar el feminicidio en Ciudad Juárez y lograr centrar los capítulos de violencia contra las mujeres como un fenómeno que no puede ser abordado dentro de la mal llamada "violencia doméstica o familiar", algo que ha ocurrido durante muchos años y aún hoy sigue ocurriendo, aunque, es cierto, en menor medida, minimizando estos crímenes al reducirlos a asesinatos "pasionales".

Debemos entender esta lucha por visibilizar los hechos dentro de un contexto misógino y patriarcal que ha sido y es combatido aún hoy por activistas y periodistas, quienes acentúan la prioridad de emplear un lenguaje adecuado, no sexista, que excluya connotaciones que puedan desvirtuar la realidad y/o aportar argumentaciones misóginas, como ha ocurrido a lo largo de todos estos años y, sobre todo, que visibilice y analice esta realidad oculta. La importancia de una terminología adecuada y específica se refleja de forma nítida en la utilización del término feminicidio para referirse a un fenómeno concreto, como el asesinato de una mujer por el mero hecho de serlo y que define muchos de los capítulos documentados en Ciudad Juárez. La defensa 
de este término para visualizar el asesinato sistemático de niñas y mujeres en Juárez, ha sido rebatido por los propios poderes públicos y políticos del Estado, así como importantes empresarios de Ciudad Juárez y periodistas, que han eliminado tradicionalmente la palabra feminicidio de sus declaraciones públicas y trabajos, optando por emplear el término homicidio de mujeres o asesinato de mujeres con una clara intencionalidad: minimizar los hechos y englobar un fenómeno específico dentro de un contexto global de violencia. Sirva como ejemplo el comunicado de prensa emitido por la Fiscalía General del Estado, el 10 de junio de 2013, a través del cual las autoridades anunciaban la detención de diez hombres y dos mujeres, acusados de formar parte de una red que estaría detrás de los secuestros y feminicidios de al menos 11 adolescentes, cuyos restos fueron localizados en el Valle de Juárez. En su comunicado, la Fiscalía obvia la palabra feminicidio, afirmando que a las personas detenidas se les imputan cargos de "trata de personas" y "homicidio agravado", empleando hasta en tres ocasiones este término.

Tanto periodistas como altos cargos públicos y políticos han puesto en duda de manera constante la gravedad y la magnitud de estos feminicidios, tratando de minimizar, e incluso cuestionar, estos crímenes, reduciendo todo a una "leyenda negra" para "generar mala fama" a la ciudad, como llegó a asegurar, en febrero de 2015, el alcalde de Ciudad Juárez, Enrique Serrano Escobar (Martínez, 2015) o, más recientemente, el analista Francisco Ortiz, quien en su artículo de opinión "Mujeres desaparecidas ¿Realidad que lacera o mito que daña?" publicado por El Diario, señalaba que "el tema de los feminicidios en Juárez ha dañado nuestra imagen como ciudad, por décadas ... Ciudad Juárez sigue siendo estigmatizada, injustamente, sobredimensionando casos emblemáticos que ocurrieron en el pasado" (Ortiz, 2017).

\section{La ética periodística}

A la hora de hablar de la ética periodística debemos comenzar por plantearnos qué es eso de la ética y, más concretamente, para qué sirve y qué papel juega en el ámbito comunicativo. En este sentido, entendemos la ética como aquello que nos autorregula y que nos vuelve legisladores de nosotros mismos (Restrepo, 2004), la cual se fundamenta en valores, entendiendo por valor aquello que es deseado, buscado y apreciado. En este sentido, la ética periodística sería aquella que nos guía hacia la excelencia con una clara finalidad cívica y social (Cortina, 2009).

Por todo ello, a la hora de desarrollar la labor informativa, esta guía debe estar presente mediante la priorización de valores que den sentido y articulen nuestra labor profesional. Es en dicho punto donde difieren posicionamientos de redactores y medios, potenciando valores y principios opuestos entre sí. Así, frente a la visión del periodismo objetivista (Galdón, 1994) que defienden algunos reporteros, basada en la defensa de una labor informativa que se limita 24 a narrar los hechos y a reproducir declaraciones de forma aséptica buscando 
una supuesta objetividad, otros autores defienden la necesidad de impulsar un periodismo investigativo y social que ejerza una función de contrapoder y se esfuerce en vincular y visibilizar muchos de los temas que afectan a los y las ciudadanas, con la posibilidad de ejercer los derechos y que humanice las noticias, mostrando que detrás de las estadísticas que centran las informaciones hay personas condicionadas por situaciones de desigualdad (Cytrynblum, 2009), promoviendo y defendiendo los derechos humanos.

Es necesario reivindicar que, optar por la segunda opción (periodismo social que defienda los derechos humanos), no tiene por qué implicar una apuesta por la subjetividad o la parcialidad, teniendo en cuenta, además, que la objetividad plena debe ser un fin, no un medio, por lo que el valor que debe primar en la labor informativa es o debería ser la honestidad del reportero (Restrepo, citado por Poveda, 2009). Debe o debería ser prioritario, en la función periodística, perseguir y denunciar las posibles negligencias o actuaciones corruptas de miembros de las fuerzas de seguridad o altos cargos de la Fiscalía ante un caso de secuestro o feminicidio antes que fomentar o dar cobertura a argumentaciones falsas o respuestas manipuladas de las autoridades. El periodista no es ni debe ser juez, pero tampoco puede limitar su función a ser un mero altavoz. El informador debe investigar, documentar e interpretar la realidad, ya que en esa pretendida neutralidad también pueden darse carencias o errores como, por ejemplo, la descontextualización de los hechos (Galdón, 1994).

Frente a los defensores de una visión de la práctica periodística objetivista, en la que los medios deben limitarse a ser transmisores de los mensajes dando una cobertura a todas las partes implicadas, incluidas autoridades o victimarios para alcanzar la "neutralidad", se sitúan los reporteros que apuestan por un periodismo de investigación y denuncia social, que evidencie las posibles negligencias gubernamentales y ponga en duda los argumentarios "oficiales" impulsados desde las diferentes administraciones. El periodismo de investigación y de denuncia se ha convertido en una herramienta fundamental frente a la reducción de la práctica periodística como una sucesión de hechos o declaraciones. Un factor primordial y muchas veces obviado es la ausencia de una perspectiva de género en la labor de contextualización $\mathrm{y}$, consecuentemente, en el tratamiento informativo. Esta ausencia de una formación en género de los redactores contribuye a la minimización de los hechos y a la proliferación de trabajos carentes de una perspectiva básica para entender y analizar esta realidad.

A pesar de que en los últimos años se han logrado algunos avances en este sentido, aún hay mucho trabajo por delante para lograr una apuesta periodística que redunde en el análisis desde una perspectiva de género. En este sentido, aún siguen existiendo medios que abogan por abordar estos hechos como sucesos en la llamada "nota roja" o de sucesos, restando importancia a los feminicidios y englobándolo dentro un contexto generalizado 
de violencia, sin discernir que nos situamos ante crímenes de género en los que niñas y mujeres son secuestradas, violadas y asesinadas por el simple hecho de ser mujeres. Igualmente, se sigue recurriendo a términos erróneos como "violencia intrafamiliar" para abordar casos de violencia de género o minimizando crímenes feminicidas al calificarlos como asesinatos "pasionales", llegando incluso, en algunos casos, a "inculpar" y justificar a los victimarios.

Algunos medios y periodistas han actuado como altavoces de las argumentaciones oficiales sin ejercer ningún tipo de análisis previo ni tampoco cuestionando los datos aportados. En este sentido, es habitual observar cómo algunos medios tratan de generalizar actitudes poco responsables de algunas adolescentes que se ausentan de forma voluntaria de sus hogares para identificarlas con los casos de jóvenes víctimas de desaparición forzada. De este modo, el medio se convierte en cómplice de la estrategia gubernamental enfocada a reducir más de 150 desapariciones forzosas de mujeres documentados entre 2008 y 2017 en Ciudad Juárez, a capítulos de huidas voluntarias de adolescentes con sus novios. No es baladí la actitud de algunos medios, reproduciendo desde el titular las afirmaciones oficiales, ya que esta actitud potencia la campaña desinformativa orquestada desde las propias autoridades. Otra estrategia impuesta a lo largo de los últimos años para la culpabilización de las víctimas es ligar, sin investigación previa alguna, a las victimadas a estructuras delictivas, justificando, de este modo, su posible secuestro, violación y asesinato. Esta estrategia gubernamental ha sido una constante a lo largo de los últimos 25 años, recurriendo a tópicos y estereotipos misóginos encaminados a justificar los feminicidios mediante argumentos falsos y sexistas. En este sentido, algunos medios incluso han dado credibilidad y cobertura a los argumentos expuestos por los propios victimarios y recurriendo al socorrido "ella se lo buscó", con mensajes que redundan en justificar que es:

la víctima la causante del delito que se comete en su contra, ya que de manera constante los agentes estatales mexicanos señalan que las mujeres y las niñas se buscaron ser desaparecidas/secuestradas, violadas, sometidas a torturas y asesinadas. "Ella se lo buscó" es una afirmación que refleja la ideología patriarcal de la sociedad mexicana y que muestra la construcción social que se ha llevado a cabo acerca de lo que significa ser hombre o ser mujer en México, particularmente en Ciudad Juárez (Sordo, 2012, p. 1).

\section{Conclusiones}

Los medios de comunicación juegan un papel prioritario a la hora de combatir la red de silencio e impunidad que rodean al feminicidio sistemático de niñas y mujeres de Ciudad Juárez. Por ello, los y las periodistas deben ser el eje sobre el que se vertebre la acción de combate contra la manipulación y la red desinformativa impulsada desde el propio Gobierno y los actores que ostentan el poder. 
La obligación los(as) periodistas, como profesionales que buscan informar de forma honesta, veraz y completa es contextualizar los hechos y desarrollar una labor analítica y crítica siempre con una perspectiva de género transversal, vital para conseguir una lectura completa y eficaz de los hechos. Las y los reporteros no pueden ser simples transmisores de mensajes, ni dar cobertura a autoridades corruptas y/o misóginas que secundan mensajes infames buscando la justificación de un feminicidio de Estado mediante la culpabilización de las víctimas. Las y los periodistas no pueden ni deben buscar la "neutralidad" ante estos hechos, sino que han de potenciar su función de contrapoder y evidenciar las negligencias y complicidades gubernamentales. En este sentido, el papel jugado por algunos medios y reporteros de Ciudad Juárez a lo largo de los últimos 25 años ha sido, cuanto menos, benevolente ante las graves negligencias e irregularidades cometidas por altos cargos públicos, políticos, judiciales y policiales del Estado.

La apuesta por un supuesto periodismo objetivista limita una lectura crítica de los hechos y un análisis de los mismos desde una óptica de género. Al reproducir los mensajes oficiales sin filtro o análisis propios del reportero se contribuye, conscientemente o no, a la difusión de mensajes manipulados. El periodismo de investigación y denuncia es fundamental para combatir la frivolización, la manipulación y el amarillismo. La ética debe ser la guía que marque las pautas, los límites y el camino a seguir y para ello es fundamental lograr un acuerdo de mínimos, una ética de mínimos (Cortina, 2009) que ayude a superar carencias y posturas que potencian la desinformación de la sociedad. La repetición sistemática de estereotipos, la frivolización o la ausencia de contraste y rigor de algunas informaciones han contribuido a potenciar una preocupante desinformación, facilitando, además, la consolidación de las diferentes estrategias de manipulación informativa impulsadas desde las diferentes autoridades.

El uso intencionado del lenguaje también juega un papel primordial. En este sentido, lograr la visibilización de lo invisible es un paso fundamental para su erradicación. Por ello, la introducción del término feminicidio para referirse al asesinato de una mujer por el simple hecho de ser mujer supuso un avance fundamental en la conceptualización y la visibilización de un fenómeno que era reducido a violencia intrafamiliar o pasional.

La lucha por una sociedad más justa y equitativa pasa irremediablemente por la consecución de un periodismo con perspectiva de género, comprometido y honesto, que supere encorsetamientos sexistas y condene de forma abierta y directa conductas o respuestas machistas ante hechos tan graves como los feminicidios y las desapariciones forzosas de mujeres y niñas en Ciudad Juárez que no son leyenda negra ni son ficción, sino una realidad que hoy, a más 25 años después de las primeras denuncias, sigue presente. 


\section{Referencias}

Castells, Manuel. (2009). Comunicación y poder. Madrid: Alianza Editorial.

Cortina, Adela. (2009). Ética de la razón cordial. Educar en la ciudadanía. Madrid: Ediciones Nobel.

Cytrynblum, Alicia. (2009). Periodismo social. Una nueva disciplina. (2da ed.). Argentina: La Crujía Ediciones.

Foucault, Michel. (1999). Las mallas del poder. En Estética, ética y hermenéutica (pp. 235-254). (Nol. III). Barcelona: Paidós.

Galdón López, Gabriel. (1994). Desinformación, método, aspectos y soluciones. (2da ed.). Navarra: Ediciones Universidad de Navarra.

García, Agustín. (2002). Superar la desmemoria y combatir la desinformación como condiciones inexcusables de una sociedad democrática. Ponencia presentada en el Ciclo de otoño del Curso organizado por la Universidad Complutense de Madrid y la Universidad Pontificia de Salamanca, España. Recuperado de http://www2.uned.es/ntedu/espanol/master/segundo/modulos/comunicacion\%20audiovisual/matilla.pdf

Giletti, Silvia. (2014). Los crímenes de género y sus huellas: Aproximación al femigenocidio. DEP. Departate, esuli, profugbe. Revista Telemática Di Studi sulla Memoria Femmminile, (24), 1-17. Recuperado de http://www.unive.it/ media/allegato/dep/n24-2014/Ricerche/01_Giletti.pdf

González Rodríguez, Sergio. (2002). Huesos en el desierto. Barcelona: Anagrama.

Incháustegui Romero, Teresa y López Barajas, María de la Paz. (Coords.). (2012). Violencia feminicida en México. Características, tendencias y nuevas expresiones en las entidades federativas, 1985-2010. México: Comisión Especial para el Seguimiento de los Feminicidios, LXI Legislatura. Cámara de Diputados-ONU Mujeres-Instituto Nacional de las Mujeres. Recuperado de http://observatoriofeminicidiomexico.org.mx/wp-content/uploads/2013/09/ violFeminicMx-1985-2012-nal.pdf

Juárez Rodríguez, Javier. (2015). Estrategias y campañas de desinformación gubernamental y manipulación informativa en relación a los feminicidios y secuestros de mujeres y niñas en Ciudad Juárez entre 1993 y 2013 (tesis de doctorado en Periodismo). Universidad Complutense de Madrid, España. Recuperada de http://eprints.sim.ucm.es/33366/1/T36463.pdf

Kapuscinski, Ryszard. (2002). Los cínicos no sirven para este oficio. Sobre el buen periodismo. Barcelona: Anagrama. 
Lagarde y de los Ríos, Marcela. (2012). El feminismo en mi vida. Hitos, claves y topías. México: HORAS Y HORAS.

Limas, Alfredo y Ravelo, Patricia. (2002). Feminicidio en Ciudad Juárez: Una civilización sacrificial. El Cotidiano, 18(111), enero-febrero, 47-57. Recuperado de http://www.elcotidianoenlinea.com.mx/pdf/11106.pdf

López García, Xosé. (2010). La metamorfosis del periodismo. Historia de lo que permanece y de lo que cambia en el ciberperiodismo del tercer milenio. Sevilla-Zamora, España: Comunicación Social. Ediciones y Publicaciones.

Martínez Huerta, David. (20 de febrero de 2015). Feminicidios en Juárez son "leyenda negra" para generar "mala fama", afirma el Alcalde. Sin Embargo. Recuperado de http://www.sinembargo.mx/20-02-2015/1257695

Ortiz Bello, Francisco. (14 de julio de 2017). Mujeres desaparecidas ¿Realidad que lacera o mito que daña? El Diario. Recuperado de http://diario.mx/ Opinion/2017-07-13_5101bc42/mujeres-desaparecidas-_realidad-que-lacera-o-mito-que-dana/?-\%2F

Poveda, Francisco. (3 de junio de 2009). RE: Javier Darío Restrepo: 'El periodista tiene que ser honesto porque no puede ser objetivo'. Periodismo para periodistas [blog]. Recuperado de http://periodismoparaperiodistas.blogspot.com.co/2009/06/javier-dario-restrepo-el-periodista

Ravelo Blancas, Patricia. (2008). El fenómeno del feminicidio: Una propuesta de recategorización. Universidad de Texas: Texas ScholarWorks. Recuperado de http://hdl.handle.net/2152/4068

Ravelo Blancas, Patricia. (2011). Miradas etnológicas. Violencia sexual y de género en Ciudad Juárez, Chihuahua. Estructura, política, cultura y subjetividad. México: Ediciones Eón /Universidad Autónoma Metropolitana, Unidad Iztapalapa / Chicano Studies - The University of Texas at El Paso / Consejo Nacional de Ciencia y Tecnología / Centro de Investigaciones y Estudios Superiores en Antropología Social.

Restrepo, Javier Darío. (2004). El zumbido y el moscardón. Taller y consultorio de ética periodística. México: Fondo de Cultura Económica. Fundación para un nuevo periodismo iberoamericano.

Robles, Humberto. (2010). Ciudad Juárez: donde ser mujer es vivir en peligro de muerte. PAPELES de relaciones y cambio global, (109), 95-104. Recuperado de http://www.fuhem.es/media/ecosocial/file/Paz/Observatorio\%20de\%20conflictos/ciudad\%20Juarez_H.ROBLES.pdf

Segato, Rita Laura. (2013). La escritura en el cuerpo de las mujeres asesinadas en Ciudad Juárez: Territorio, soberanía y crímenes de segundo estado. 
Buenos Aires: Ediciones Tinta Limón. Recuperado de http://www.feministas.org/IMG/pdf/rita_segato_.pdf

Sordo, Tania. (2011). Ella se lo buscó: Estereotipos de género en el Estado mexicano: Sentencia Campo Algodonero. XV Premio SIEM de Investigación feminista Concepción Gimeno de Flaquer. España: Universidad de Zaragoza. Recuperado de http://wzar.unizar.es/siem/PREMIOS/XV\%20 Premio\%20SIEM\%20de\%2OInvestigacion\%2Ofeminista\%20-\%20Tania\%20 Sordo\%20R.pdf

Tajahuerce Ángel, Isabel (Coord.). (2014). Mujeres y comunicación. Madrid, España: La Linterna Sorda.

Toledo Vásquez, Patsili. (2009). Feminicidio. México: Oficina en México del Alto Comisionado de las Naciones Unidas para los Derechos Humanos.

Varela, Nuria. (2005). Feminismo para principiantes. Barcelona: Ediciones B.

Washington Valdez, Diana. (2005). Cosecha de Mujeres: Safari en el desierto mexicano. Barcelona: Océano. 